\title{
La ausencia presente de Nietzsche en Ser y tiempo. Proximidad entre el concepto nietzscheano 'interpretación' y el heideggeriano 'comprensión'
}

\author{
MANUEL TORRES VIZCAYA \\ IES «Val Miñor», Pontevedra
}

El trabajo quiere indagar y rastrear la huella de Nietzsche en Sein und Zeit, reconstruir la ausencia presente o la presencia ausente de aquél en una de las obras más significativas de la filosofía contemporánea. Consideraremos que tal complicidad existe aunque, desde luego, viene siendo ignorada de forma sistemática, principalmente por el jalonamiento que tan exitosamente ha establecido la potentísima fuerza gravitatoria del Nietzsche de Heidegger. La versión canónica mantiene, como señala paradigmáticamente Pöggeler, que «Nietzsche sólo llegó a ser decisivo para Heidegger en los años inmediatamente siguientes a la aparición de Ser y Tiempo» ${ }^{1}$. Sin embargo, queremos sugerir que, al margen de ese manido tópico, el pensamiento de Nietzsche, al menos en lo que se refiere a ciertos conceptos, representa un papel determinante en la obra de 1927 y que ésta supondría una suerte de continuación, no precisamente como un mero mimetismo escolar sino, más bien, como repetición de una determinada temática. Esta conexión se hace, a nuestro juicio, manifiesta característicamente en la vinculación que se puede establecer entre el concepto nietzscheano Auslegung y el heideggeriano Verstehen.

\section{1. ÁMBITO DE LA INTERPRETACIÓN}

La idea que guía nuestro trabajo podría formularse así: Heidegger continúa en Sein und Zeit la tarea nietzscheana de revolucionar el problema tradicional del conocimiento y, a una con ello, la tarea de destrucción de la teoría del conocimiento. Ello supone no sólo la prolongación de la crítica de una disciplina -elemento, por cierto, en el que Nietzsche no se detuvo en exceso por ser de suyo un corolario obvio- sino, y lo que es más importante, al mismo concepto de conocimiento. Según esto, Heidegger problematizaría el conocimiento en unos

${ }^{1}$ O. Pöggeler, El camino del pensar de M. Heidegger, tr. Félix Duque, Alianza, Madrid, 1986, p. 111. 
cauces estructuralmente semejantes a los nietzscheanos, tratando de encontrar -es lo que hace su desarrollo característico- su fundamento ontológico. En tal sentido es en el que podemos nombrar a Heidegger como prolongador de la crítica nietzscheana al conocimiento. El esfuerzo por desenmascarar los oscuros vericuetos del logos inicial, transmutado permanentemente en conocimiento, se concreta en el concepto nietzscheano de interpretación (Auslegung) y el heideggeriano de comprensión (Verstehen). Según Gadamer, «cuando Heidegger caracteriza y acentúa la comprensión considerándola como el movimiento básico de la existencia, desemboca en el concepto de interpretación, que Nietzsche había desarrollado especialmente en su significado teórico» ${ }^{2}$. Desarrollar y completar esta idea gadameriana, también presente en otros autores como Figl o Vattimo, es lo que nos proponemos.

La interpretación no es un concepto subsistente en sí mismo o que funcione independientemente dentro del marco global de la filosofía de Nietzsche sino que es el epicentro de una compleja estructura que supone de facto la reformulación del esquema tradicional del logos mismo. Podría decirse que la interpretación es el elemento central de una estructura doble que estaría constituida por la vida como voluntad de poder y el Übermensch. Lo decisivo de este esquema es que en él está concentrada toda la tarea y el esfuerzo transformador del logos y su degeneración unilateral en conocimiento. En multitud de ocasiones identifica Nietzsche voluntad de poder con la vida y el mundo en general ${ }^{3}$. La voluntad de poder no es un ser ni un devenir sino un pathos, aquel hecho elemental del cual resulta lógicamente todo devenir y obrar: «la voluntad de poder no es un ser, no es un devenir sino un pathos - es el hecho elemental, del cual resulta un devenir, un obrar» ${ }^{4}$. Es, entonces, la voluntad de poder la que introduce, en último término, el sentido en las cosas: «todo sentido es voluntad de poder» ${ }^{5}$. La interpretación es una macroproposición que garantiza todo interpretar y, a la

${ }^{2}$ G. Gadamer, Verdad y método II, tr. M. Olasagasti, Sígueme, Salamanca, 21994; p. 105. Según Gadamer, Heidegger proseguiría la tarea de Nietzsche al confirmar que «la interpretación no es un recurso complementario del conocimiento, sino que constituye la estructura originaria del "ser-en-el-mundo"» (p. 328). Sin embargo, la conexión gadameriana entre el carácter interpretativo-comprensor de la existencia en Heidegger y la interpretación en Nietzsche no debe conducirnos a pensar que este autor haya desarrollada dicha conexión sino, a lo sumo, anunciarla. Gadamer se queda siempre, hasta donde alcanzamos a saber, en la mera formulación de la conexión pero no profundiza en ella. La conexión entre interpretación y comprensión es la hipótesis de trabajo que se plantea precisamente Figl; cf. J. Figl Interpretation als philosophisches Prinzip, W. De Gruyter, Berlin, 1982, p. 31. Recientemente J. Grondin se ha sumado a la retahíla de autores que sitúan a Nietzsche como iniciador de la hermenéutica pero sin demostrar concretamente la razón; para Grondin el 'panhermeneutismo' de Nietzsche desemboca en la hermenéutica continental (cf. J. Grondin, Introducción a la hermenéutica filosófica, tr. Angela Ackermann, Herder, Barcelona, 1999, p. 35ss.).

${ }^{3}$ Cf. por ejemplo KSA XII 161: 2[190] y KSA XI 610-611: 38[12].

${ }^{4}$ KSA XIII 259: 14[79].

${ }^{5}$ KSA XII 97: 2[77]. 
vez, cada interpretación concreta es resultado de la actuación - por causalizar y escindir- de la voluntad de poder y así el interpretar mismo es una forma de la voluntad de poder. Cada interpretación es un medio privilegiado que pretende dominar algo y, en la misma medida, se cumple el designio de lo orgánico. En suma, la voluntad de poder es el protoelemento que posibilita la interpretación. Este carácter proteico impide ya de suyo cualquier consideración sustancialista de la voluntad de poder como principio metafísico en sentido estricto. Es previo a cualquier fundamento lógico, en la medida en que la lógica es una perspectiva proveniente de una determinada interpretación, aunque ciertamente la más exitosa.

La comprensión de la vida como voluntad de poder conlleva específicamente una redefinición del objeto tal y como el logos lo entendió desde los griegos, esto es, como secuencia fija divisible en sujeto-objeto y también de la objetividad como criterio de verdad. La relación con el sujeto, instancia todopoderosa de la ratio metafísica, viene ahora a entenderse dentro del marco de ese sujeto reciclado que es el Übermensch. La interpretación es conformadora y conformada por la vida entendida como voluntad de poder, lo cual dista notablemente del esquema tradicional en el que el conocimiento debía aplicarse al objeto. El mundo, conjunto de objetos sobre los que se vertía la reflexión, es trastocado en la vida como voluntad de poder, esto es, el mundo se 'descentraliza' y la objetividad ya no podrá hacer las veces de paradigma para interpretar la realidad. El sujeto, por su parte, aparece redefinido esencialmente, en la medida en que el Übermensch no es esa estructura fija y sempiterna donadora de seguridades celestiales a quien se le encargaba, en último término, el conocimiento de todo. En forma resumida, quizás ciertamente en demasía, puede decirse que el esquema pregnante y normativo desde Platón y cuya fórmula podría ser conocimiento: sujeto-objeto, es reconvertido en interpretación: Übermensch - vida como voluntad de poder. El fenómeno de la interpretación en Nietzsche es un elemento lo suficientemente complejo como para admitir diversos grados y espesores. Globalmente la interpretación puede entenderse -al menos polémicamente-como alternativa al fenómeno del conocimiento y, precisamente en este sentido, conecta con lo que, también genéricamente, llama Nietzsche 'sabiduría trágica' o 'conocimiento trágico'. A través de la interpretación y su radio de influencia aquello a lo que apunta Nietzsche es a una auténtica reconstrucción de ese logos establecido monotemáticamente desde los inicios del pensar occidental.

Esta señalada estructura tripartita -voluntad de poder, interpretación e Übermensch- no sólo cuestiona sino que, en rigor, elimina el carácter incondicional que el logos se había autoimpuesto, con todo lo que ello representa en cuanto a los mecanismos de legitimación de la interpretación de la realidad $\mathrm{y}$, por ende, a su fundamento último. Es preciso observar, en este sentido, que no se discute ahora si la interpretación concreta que Nietzsche asume (más que la interpretación como metainterpretación) es de suyo merecedora de ser 
considerada como superación de la subjetividad fundante y de la metafísica misma sino, precisamente, que el mismo esfuerzo genérico nietzscheano -puede hasta decirse formalmente- ya lleva aparejado inextricablemente la quiebra del monopolio de una determinada interpretación del logos. Frente a la interpretación del Nietzsche de Heidegger que se centra básicamente en si el autor de Zaratustra supera o no el pensamiento metafísico, puede considerarse, desde un punto de vista formal, que, independientemente de la 'solución' de Nietzsche, éste quiebra la confianza definitivamente en la interpretación tradicional que arranca del logos inicial ${ }^{6}$. La estructura tripartita mencionada es preciso entenderla en sus justos términos, esto es, como una auténtica estructura relacional que deshereda eternamente el vicio inveterado de lo anhipotético ${ }^{7}$.

\section{EL PAPEL DE LA CONCIENCIA}

La estructura de la interpretación a la que hemos aludido puede considerarse como el esqueleto externo o genérico pero falta todavía preguntarse por la estructura interna de esa interpretación, esto es, por su raigambre y contenido último. La conciencia es uno de los elementos claves en el desarrollo de la crítica de toda la metafísica, de aquella metafísica que forzó el logos inaugural fijándole un solo camino: el conocimiento. La conciencia, «la exageración desmedida en la estimación de la conciencia», consistente en que «cualquier progreso reside en el progreso hacia la conciencia; todo retroceso reside en la inconsciencia» ${ }^{8}$, es uno de los grandes errores de toda la cultura occidental. La conciencia, tanto filosófica como psicológica e incluso fisiológicamente, representa las taras fundamentales de la entera filosofía occidental. Ahora bien, lo que interesa ahora es señalar e insistir en el carácter derivado y ficticio de la conciencia y esto sólo es posible desde su fuente misma.

Para Nietzsche la conciencia está en dependencia directa con la vida orgánica preconsciente del cuerpo, esto es, la conciencia es el reflejo y consecuencia 'lógica' de lo orgánico. No cabe duda, entonces, de que «todo lo que deviene consciente ha sido previamente dispuesto, simplificado, esquematizado, interpretado» ${ }^{9}$. La conciencia es una interpretación bien determinada que trastoca y convierte los estímulos en causas según las necesidades del caso: «toda nuestra llamada conciencia [es] un comentario más o menos fantástico sobre un texto desconocido, quizás imposible de conocer, pero sentido» ${ }^{10}$. Es

\footnotetext{
${ }^{6}$ Cf. M. Heidegger, Nietzsche, Neske, Pfullingen, 2 vols., 1961, vol. I, p. 473ss.

${ }^{7}$ Puede interpretarse esto en el sentido de una primacía de la interpretación y del carácter interpretable de todo, por así decir, sin cortapisas; cf. M. Foucault, «Nietzsche, Freud, Marx» en Cahiers de Royaumont, Minuit, Paris, pp. 183-192.

${ }^{8}$ KSA XIII 330: $14[146]$.

${ }^{9}$ KSA XIII 53: 11[113].

${ }^{10}$ M: KSA III 113.
} 
claro que lo que define al ser orgánico es su capacidad de interpretación, de tal forma que puede imponerse, de alguna manera, a la realidad: «lo esencial del ser orgánico es una nueva interpretación del acontecer» ${ }^{11}$. Esa interpretación que, arrancando de la médula misma de lo orgánico, degenera en conciencia implica una determinada visión de la realidad de carácter reactivo y, por tanto, asfixiante por definición del flujo vital. Se trata de entender que «el mundo visto, sentido e interpretado de tal y cual forma, de suerte que la vida orgánica se conserve bajo esta perspectiva de interpretación. El hombre no es solamente un individuo sino la integridad de lo orgánico subsistente, en una línea única y determinada» ${ }^{12}$.

Lo que hace Nietzsche es, por una parte, poner en entredicho el carácter autónomo de la conciencia y, por ende, del conocimiento y, por otra, redefinir todo lo consciente y sus representaciones desde una esfera previa de carácter inconsciente. La concepción y el edificio entero de la racionalidad entra decididamente en crisis y «lo hace a través de un cuestionamiento entre las pulsiones [Triebe] y el conocimiento [...] El señalamiento de la función de las pulsiones en la determinación de la racionalidad lleva necesariamente a poner en juego todo tipo de discurso cognoscitivo» ${ }^{13}$. El $\log o s$ y su interpretación normativa -el ideal del conocimiento- aparece fuertemente cuestionado al descubrirse que «nuestro saber es la forma más debilitada de nuestra vida pulsional» ${ }^{14}$. Saber que el mundo no es más que un síntoma y sublimación de las pulsiones dominantes deja en entredicho a la ratio y cuestiona fuertemente a la conciencia y al sujeto como fundador de realidades. El modo fundamental de abrirse al mundo desde el sujeto ponente como mecanismo único es sustituido o, mejor dicho, ampliado con otra apertura diferencial. Como muy bien señala Vermal: «al anteponer la función de las pulsiones a la de la reflexión racional, Nietzsche quiere señalar primordialmente no un elemento biológico como base del conocimiento sino el carácter de apertura del mundo que tiene lo que llama 'pulsión' ante la cual la determinación del sujeto como polo de conocimiento y actividad resulta en el mejor de los casos secundaria y derivada» ${ }^{15}$. Además, el origen de la institucionalización y dictadura del 'conocer consciente' tiene una localización histórica muy concreta. El responsable, como no podía ser de otra manera, es Sócrates quien inició una exitosa «psicología rudimentaria que no valora más que los momentos conscientes en el hombre» ${ }^{16}$.

${ }^{11}$ KSA XII 17: 1[28]. Cf. también KSA XII 140: 2[148].

${ }^{12}$ KSA XII 251: 7[2]. «Interpretación. Hasta qué punto las interpretaciones del mundo son síntoma de un impulso dominante» KSA XII 256: 7[3].

${ }^{13}$ J.L. Vermal, La crítica de la metafísica en Nietzsche, Anthropos, Barcelona, p. 67.

${ }^{14}$ KSA IX 210: 6[64].

${ }^{15}$ J.L. Vermal, op. cit., p. 70.

${ }^{16}$ KSA XIII 310: 14[129]. 


\section{El MODELO APOLÍNEO-DIONISÍACO}

Con esta 'bipolaridad' no aludimos patentemente a un mero episodio de una obra primeriza sino a uno de los pivotes fundamentales de la reflexión nietzscheana y que ciertamente culmina en la noción de interpretación ${ }^{17}$. Compartimos así la declaración de Vattimo según la cual en la primera filosofía de Nietzsche se presenta «un concepto central, original y característico, que puede tomarse como hilo conductor para leer toda su obra: es la pareja apolíneo-dionisíaco» ${ }^{18}$. Si en Die Geburt der Tragödie parece que lo apolíneo y lo dionisíaco se oponen, en general, como dos instintos, con posterioridad será el elemento dionisíaco quien absorba a lo apolíneo. Con todo, se da una 'alianza fraternal' entre las dos divinidades de tal forma que «Dioniso habla el lenguaje de Apolo, pero al final Apolo habla el lenguaje de Dioniso; con lo cual se ha alcanzado la meta suprema de la tragedia y del arte en general» ${ }^{19}$. Independientemente, lo que si puede afirmarse con rotundidad es la imposibilidad de entender la relación entre ambos términos en el sentido de una Aufhebung dialéctica y ello aunque aparentemente la obra nos induzca a interpretar el asunto en ese sentido. Al menos retrospectivamente vista, la filosofía de Nietzsche, como dice Deleuze, forma una «antidialéctica absoluta» ${ }^{20}$. La tragedia supone la reconciliación dominada por Dioniso en tanto que el drama es la objetivación de Dioniso bajo una forma expresamente apolínea; esta reconciliación lleva pareja la tendencia hacia la unidad: «con la palabra dionisíaco se expresa un impulso hacia la unidad $»^{21}$.

Podría decirse que Apolo y Dioniso no representan los términos antitéticos de una posible contradicción sino que, antes bien, son dos modos antitéticos de resolverla ${ }^{22}$. Esos dos modos son el conocimiento trágico de la existencia frente al conocimiento, a la unilateralización del logos. Una vez que lo apolíneo se ha impuesto, que el logos ha seguido una muy determinada senda, lo único que queda es indagar desde dónde surge precisamente ese carácter apolíneo y cómo hay que entenderlo. Esta indagación de la procedencia y el origen no sólo nos acerca al carácter estrictamente genealógico sino que patentiza paradigmáticamente la circularidad, en la medida en que lo apolíneo es manifestación de un previo instinto dionisíaco que, eso si, ha podido ser

\footnotetext{
${ }^{17}$ En otro lugar hemos querido vincular programáticamente El nacimiento de la tragedia y Ser y tiempo, cf. «Del problema del conocimiento al conocimiento como problema. Una aproximación entre Ser y tiempo y El nacimiento de la tragedia», Estudios filosóficos, 150, 2003, 289-310.

${ }^{18}$ G. Vattimo, Introducción a Nietzsche, tr. J. Binaghi, Paidós, Barcelona, 21990; p. 15.

${ }^{19}$ GT: KSA I 140, NT, ed. A. Sánchez Pascual, p. 172.

${ }^{20}$ G. Deleuze, Nietzsche y la filosofía, tr. Carmen Artal, Anagrama, Barcelona, 31993, p. 271.

${ }^{21}$ KSA XIII 224: 14[14].

${ }^{22}$ Cf. G. Deleuze, op. cit., pp. 21-22.
} 
causalizado y canalizado de forma muy peculiar en la historia de la filosofía. Declara Nietzsche que «en el fondo, yo no trataba más que adivinar por qué el apolinismo griego había madurado siempre en un subsuelo dionisíaco» ${ }^{23}$. A pesar de que Nietzsche reconoce la falta en su primera obra de un «lenguaje propio» ${ }^{24}$, parece más o menos claro que lo dionisíaco es la auténtica precomprensión de la vida, aquello que nos sitúa en contacto con nuestra existencia en una forma, digamos, rudimentariamente efectiva y afectiva. Cuando la lógica se enrosca sobre sí misma, dice Nietzsche, irrumpe una «nueva forma de conocimiento, el conocimiento trágico» ${ }^{25}$.

El conocimiento trágico no es más que, por una parte, la toma de conciencia de la relatividad del conocer humano, esto es, el cuestionamiento permanente de la victoria de la dramatización apolínea y, por otra, apunta a un nuevo enfoque en el tratamiento e interpretación del logos. La 'sabiduría instintiva' que fue inicialmente canjeada y transmutada en 'conocer consciente' socrático no pretende un nuevo ajuste de cuentas dialéctico -lo cual sería, por otra parte, situarse a la misma altura del esfuerzo racionalizador socrático- que anule el otro extremo sino comprender el fondo mismo, el móvil del conocimiento y, en la misma medida, operar desde otros supuestos que ya no sean supuestos en el sentido fuerte de la palabra. Se trata de recuperar el fondo dionisíaco olvidado y con ello recuperar también otra perspectiva de la existencia, a saber, la de que nuestro conocimiento depende de una instancia no fundante y previa. El resultado no se hace esperar: la unilateralidad de logos operada en el gesto característico euripídeo-socrático debe ser reevaluada desde la perspectiva dionisíaca. El conocimiento ha distorsionado el fondo dionisíaco a través de la tematización de la vida misma y la tarea urgente no es otra que la de recuperar ese fondo. El monopolio del logos, de una determinada forma de entenderlo, quiebra definitivamente.

\section{LA ‘COMPRENSIÓN’ EN HEIDEGGER Y SU VERTIENTE NIETZSCHEANA}

De forma paralela a como acontece en Nietzsche (voluntad de poder, interpretación e Übermensch), podemos considerar que el problema del conocimiento se vertebra en Sein und Zeit en torno a una estructura triple. El término que galvaniza y aglutina todo el planteamiento del conocimiento en la obra de 1927 es la comprensión (Verstehen), de tal forma que en derredor de ella podemos encontrar una crítica firme a la idea tradicional de ontología y, simultáneamente, una proposición respecto del 'fundamento' de cualquier

${ }^{23}$ KSA XIII 225: $14[14]$.

${ }^{24}$ Cf. GT: KSA I 19, NT p. 33. Por cierto, lo mismo le sucederá a Heidegger en relación a Sein und Zeit.

${ }^{25}$ GT: KSA I 101, NT p. 130. 
ontología. Hablar de ontología es para Heidegger hablar de conocimiento y de la idea de conocimiento concomitante con la ontología; la ontología presupone no sólo una idea de conocimiento sino que sólo es posible bajo el supuesto mismo de una interpretación del conocimiento como fuente de acercamiento a la realidad ${ }^{26}$.

El fenómeno de la comprensión apunta, desde el punto de vista estructural señalado, a un doble frente en el que adquiere su plena legitimidad. Por un lado, señala al ser en el mundo como aquella estructura a priori del Dasein que pone a éste en contacto con lo que llamamos mundo ${ }^{27}$. Por otro, nos encontramos con el Dasein, la existencia humana misma y, entendido en tal sentido, ajeno a la tradicional idea de una subjetividad ponente. El Dasein no es un ser disponible para ser meramente tematizado, conocido y explicitado teóricamente sino que justamente es comprensión en sí mismo. Ser en el mundo y Dasein vienen a implicar una clara renovación del problema del conocimiento, en tanto en cuanto buscan redefinir el papel que la tradición asignó al objeto y al sujeto de conocimiento. La comprensión resultaría así el término central en el que descansaría el redefinido sujeto y objeto de conocimiento. El mismo gesto, al menos estructuralmente hablando y mutatis mutandis, realiza Nietzsche al situar a la vida como voluntad de poder como a priori auténtico ${ }^{28}$ de todo conocimiento del mundo y al Übermensch como sujeto reciclado. La estructura tripartita que encontramos en Nietzsche, la constituida por la interpretación, la voluntad de poder y el Übermensch, se repite en Heidegger con la comprensión, el ser en el mundo y el Dasein. Esta similitud será lógicamente aclarada en lo que sigue.

Lo que se cuestiona en los dos planteamientos es la idea de conocimiento que ha dominado toda la historia de la filosofía occidental. No se trata, en modo alguno, de una idea entre otras sino, en todo caso, de la idea por excelencia, de la interpretación del logos que se ha impuesto unilateralmente. El conocimiento

${ }^{26}$ Enfatizar un existenciario ex profeso es, en el fondo, ir contra el espíritu de la obra, en la medida en que todos tienen igual cooriginariedad. No obstante, al remarcar sobremanera la comprensión pretendemos solamente destacar un elemento que actúa como clave sin, por otra parte, querer remitirlo al ámbito de los fundamentos metafísicos.

${ }^{27}$ Cf. M. Heidegger, Gesamtausgabe, vol. 2: Sein und Zeit (= SuZ), V. Klostermann, Frankfurt am Main, 1977, acompañamos la traducción española de J. Gaos en FCE, SuZ, p. 53 / 66. Como señala R. Rodríguez, «ser en el mundo es el horizonte a priori de todo conocer, icluida la autoconciencia. No hay ninguna captación de mí mismo que no sea a la vez e inevitablemente de mí en el mundo» R. Rodríguez, Heidegger y la crisis de la época moderna, Cincel, Madrid, 1987 , p. 95 . En otro trabajo hemos intentado precisar otros ángulos de la identidad programática de la obra de 1927 respecto del pensamiento de Nietzsche, al tiempo que situamos la reflexión como redefinición del giro copernicano kantiano; cf. «Derribar ídolos / derrotar quimeras. Los espesores de la crítica al logos en Nietzsche y en el Heidegger de Sein und Zeit», Pensamiento, 220, 2002, 91-121.

${ }^{28}$ «Nuestros impulsos son reductibles a la voluntad de poder. La voluntad de poder es el factum último a que descendemos» KSA XI 661: 40[61]. «El carácter de la voluntad incondicional de poder se halla presente en la totalidad del reino de la vida» KSA XII 23-24: 1[54]. 
en Nietzsche como ficción y en Heidegger como encubridor de la función ontológica del tiempo justifican que por conocimiento no nos estamos refiriendo a una mera cuestión disciplinar dentro de la filosofía. Ontología, metafísica, filosofía son nombres que designan, con diversos matices, el mismo asunto. Por tanto, la tarea no es la de descubrir solamente la paradoja inherente a todo discurso sobre el conocimiento: «roza lo ridículo el que nuestros filósofos exijan que la filosofía tenga que comenzar por una crítica de la facultad de conocer [...] La reducción de la filosofía a la "voluntad de una teoría del conocimiento" es ridícula. ¡Como si de esta manera se pudiese encontrar seguridad!» ${ }^{29}$. Para Heidegger no se trata sólo de que 'el problema del conocimiento' desfigure los problemas auténticos ${ }^{30}$ sino que la 'primacía del conocimiento' ha sido un hecho nefasto al hacer creer que el conocimiento (noein) es el modo primario del ser en el mundo ${ }^{31}$. La lectura que proponemos atañe al conocimiento como pilar básico de la metafísica occidental. Leer la obra de Nietzsche y Heidegger desde esta óptica creemos que puede aportar una perspectiva alternativa o, en todo caso, complementaria de las lecturas al uso. Desde luego sí pretende modificar, en la medida en que ello sea posible, la comprensión de la relación entre Nietzsche y una determinada parte de la obra de Heidegger.

La tarea de la propia historia de la filosofía ha determinado que Nietzsche y el llamado 'primer Heidegger' convinieran en muchos aspectos y, sobre todo, que participasen de un planteamiento genérico realmente similar. Quizás pudiéramos en esto convenir con Gadamer en el sentido de que el hecho de que Nietzsche actúe como verdadero precursor de Heidegger fue algo que éste sólo entendió más tarde: «[...] el verdadero precursor de la posición heideggeriana en la pregunta por el ser y en su remar contra la corriente de los planteamientos metafísicos occidentales no podían ser ni Dilthey ni Husserl, sino en todo caso Nietzsche. Puede que Heidegger mismo sólo lo comprendiera más tarde» ${ }^{32}$. Independientemente de las pesquisas histórico-filosóficas que se puedan hacer, puede rastrearse una presencia decisiva de Nietzsche en la obra de 1927, bien es cierto que bajo la apariencia de una, quizás, ausencia calculada.

\section{EL MODELO DIONISÍACO-HERMENÉUTICO}

Heidegger vincula la comprensión a la interpretación (Auslegung), en la medida en que «la interpretación no es el tomar conocimiento de la comprensión, sino el desarrollo de las posibilidades proyectadas en la comprensión» ${ }^{33}$. Lo

${ }^{29}$ KSA XII 26: $1[60]$.

${ }^{30}$ SuZ, p. $176 / 149$.

${ }^{31}$ Cf. SuZ, p. 79/71.

${ }^{32}$ H.-G. Gadamer, op. cit., p. 323; subrayado nuestro.

${ }^{33}$ SuZ, p. $197 / 166$. 
Zuhanden alcanza aquí su concreción ontológica y su papel específico ya que el ver antepredicativo inmerso en él viene a ser considerado por definición interpretativo-comprensor. Destaca Heidegger especialmente este carácter previo, de anterioridad del esfuerzo interpretativo-comprensor respecto de toda aprehensión temática, de todo conocimiento. «La articulación de lo comprendido en el acercarse interpretativamente de los entes siguiendo el hilo conductor de 'algo como algo' es anterior a toda proposición temática sobre ellos» ${ }^{34}$. De hecho existe una «estructura 'previa' en la comprensión» (Vor-Struktur des Verstehens) que excede lógicamente el carácter atribuido tradicionalmente a las estructuras denominadas a priori ${ }^{35}$. La interpretación se mueve en esa estructura de lo 'previo' y ello acarrea una circularidad, constituyendo el núcleo del llamado círculo hermenéutico. La interpretación no es la aprehensión 'objetiva' de algo sino que está permanentemente hipotecada, henchida de supuestos $^{36}$. Al ser la comprensión algo que caracteriza muy propiamente al Dasein, es preciso concluir que éste en cuanto ser en el mundo tiene, entonces, una marcada estructura ontológica circular. Al señalar que «el ente al que en cuanto ser en el mundo le va su ser mismo, tiene una estructura ontológica circular» ${ }^{37}$, se aprecia la relación estrecha entre los tres polos señalados: ser en el mundo, Verstehen y Dasein.

Si la estrecha relación entre comprensión e interpretación en Sein und Zeit se realiza genéricamente sobre el modelo de la Zuhandenheit, puede decirse que paralelamente la interpretación en Nietzsche se verifica sobre el modelo global de lo dionisíaco. Teniendo como estructura referencial última la vida como voluntad de poder y el Dasein como ser en el mundo, la comprensión heideggeriana y la interpretación nietzscheana sólo son especificables, entendibles y legitimables bajo la concreción de los modelos de lo dionisíaco y la Zuhandenheit. Es desde ambos modelos desde donde es posible la crítica y el teórico descabalgamiento del logos, tal como se ha venido entendiendo, como monopolio del saber ${ }^{38}$.

En Sein und Zeit el desarrollo del entendimiento de la proposición (Aussage) como modo derivado de la interpretación viene a cuestionar el sentido atribuido al logos y a descubrir el modelo ontológico sobre el que éste se ha asentado. Resulta, entonces, un hecho consumado que «para la consideración filosófica es

${ }^{34}$ SuZ, p. $198 / 167$.

${ }^{35}$ Cf. SuZ, pp. 200-201/169.

${ }^{36}$ Según Heidegger «una interpretación jamás es una aprehensión de algo llevada a cabo sin supuesto»; SuZ, p. 200/168. La interpretación tiene que haber comprendido ya lo que trata de interpretar; SuZ, p. 202/170.

${ }^{37}$ SuZ, p. 204/172.

${ }^{38}$ Conviene recordar que el modelo de la Zuhandenheit se halla perfectamente prefigurado, por lo menos, en los cursos que van de 1919 a 1922. Cf. en este sentido R. Rodríguez, La transformación hermenéutica de la fenomenología, Tecnos, Madrid,1997. 
el logos mismo un ente, y con arreglo a la orientación de la ontología antigua, un ente Vorhanden ${ }^{39}$. El dudoso privilegio de la proposición consiste en la reducción del 'como' original de la interpretación del ver en torno (Umsichtigen Auslegung) al 'como' de la determinación de la Vorhandenheit. De aquí deduce Heidegger la siguiente distinción clave: «al 'como' original de la interpretación comprensora del 'ver en torno' lo llamamos el 'como' hermenéutico-existenciario, a diferencia del 'como' apofántico de la proposición» ${ }^{40}$. De todo ello pueden extraerse dos consideraciones claras: (1) el logos tiene sus raíces ontológicas propias en la analítica existenciaria y (2) el logos tradicional, entendido bajo la estela de la Vorhandenheit, aparece él mismo como algo derivado en su esfuerzo conceptualizador. Por tanto, se pone decididamente en cuestión la base metódica de la ontología antigua y, de esa forma, su carácter no original.

Paralelamente puede establecerse, sin violentar mucho las cosas, la diferencia entre un 'como' dionisíaco-hermenéutico y un 'como' apolíneo-apofántico. La función de lo dionisíaco-hermenéutico es patentemente la misma, a saber, poner en solfa la 'base metódica' sobre la que ha sido posible el desarrollo ulterior de toda metafísica y, por el contrario, en lo apolíneo-apofántico se descubre esa precisa trama. El factor dionisíaco-hermenéutico no sólo saca a luz, en rigor, la trama de toda la metafísica sino que supone por su misma inercia un punto de vista alternativo vehiculado en la interpretación en Nietzsche y la comprensión en Heidegger. De la misma forma que el Umsicht, el ver en torno, mediado hermenéuticamente, es el contacto original con las cosas, el protoconocimiento, así la dimensión dionisíaca, el pensamiento trágico es ese mismo protocontacto con el mundo. El carácter apofántico que distorsiona -por omitir- el carácter peculiarmente hermenéutico de la existencia está en la misma posición que el pensamiento socrático-platónico respecto de la dimensión trágica del pensamiento. Si lo que denuncia el 'como' hermenéutico es el carácter diferido que se le ha infundido desde su mismo inicio al logos, lo mismo representa el pensamiento trágico, el carácter interpretativo respecto de la socratización de la cultura occidental. Y todo ello, en uno y otro caso, arraigado en un carácter hermenéutico indiscutible: la vida como voluntad de poder y el Dasein como existencia interpretativo-comprensora. Es preciso insistir, no obstante, que no se trata de una identificación rigurosa - cosa absurda, por otra parte- sino de asimilar funciones conceptuales.

\section{LÍMITES DEL CONOCIMIENTO}

En el caso de Heidegger es la facticidad como dato irrebasable del entorno propiamente humano la que, materializada en el ser en el mundo, de forma

${ }^{39}$ SuZ, p. $211 / 177$.

${ }^{40}$ SuZ, p. 210/177. 
errónea se enquistó metafísicamente a través del olvido del ser. De ahí que pueda decirse que la 'comprensión preontológica' peculiar del Dasein apunta sin fisuras a confirmar que «la forma inmediata de "andar" no es [...] el conocimiento no más que perceptivo, sino el "curarse de" [Besorgen] que manipula, que usa y que tiene su peculiar "conocimiento" ${ }^{41}$. Para Nietzsche es el carácter dionisíaco de la existencia, el conocimiento trágico el que proporciona el verdadero protoconocimiento, bajo los auspicios del arte como marco general ${ }^{42}$. La decadencia que representa la filosofía sólo puede ser compensada por el contramovimiento del arte.

En Nietzsche encontramos una peculiar circularidad que puede hallarse en la interpretación y ceñirse a dos niveles. El nivel interno, según el cual toda nuestra vida consciente, la razón misma y sus resultados, están predeterminados por factores pulsionales de carácter inconsciente. Esta sería una especie de Vorstruktur que de suyo determina cualquier tipo de interpretación y que se obvia habitualmente como apertura inicial al mundo. Podemos distinguir, en segundo lugar, un nivel externo o genérico. El planteamiento de lo inconsciente y la vida pulsional conduce inequívocamente al perspectivismo y éste viene dado por la voluntad de poder. En este caso, aparece inmediatamente cuestionada la idea de fundamento, habida cuenta de que la 'dialéctica'de la interpretación excluye cualquier instancia fundamentativa -a excepción, si se quiere, de ella misma. Cuando la voluntad de poder exige llegar a la verdad sobre lo existente parece acentuarse una clara contradicción: nada es verdad pero simultáneamente la voluntad de poder exige y funciona como criterio de verdad. Como señala Müller-Lauter, hay un círculo que pertenece a la comprensión de todo ${ }^{43}$. El propio Nietzsche señala que «el intelecto humano no puede sustraerse a verse a sí mismo en este análisis bajo sus formas perspectivistas y sólo bajo ellas. No podemos salir de esta óptica nuestra $»^{44}$. Es imposible, entonces, salirse de esa circularidad, que de suyo no carece de importancia en su sentido positivo sino que caracteriza típicamente el proceder interpretador mismo. Para Nietzsche esto tiene el rango de una -cuasi- virtud: «suponiendo que también esto sea nada más que interpretación - ¿y no os apresuraréis vosotros a hacer esa objeción? - bien, tanto mejor» ${ }^{45}$.

${ }^{41}$ SuZ, p. $90 / 80$.

${ }^{42}$ En resumidas cuentas la postura de Nietzsche es la siguiente: «una consideración antimetafísica del mundo - sí, pero artística» KSA XII 160: 2[186]. Con todo, el arte, lo que sería un "mal arte", puede actuar como elemento glorificador de los errores metafísicos (cf. MA I: KSA II 180) o adquirir máximo valor bajo «ciertos presupuestos metafísicos» (cf. MA I: KSA II 185-186) pero, por encima de todo, el arte mismo tiene la posibilidad de ser instrumento de liberación permanente (cf. FW: KSA III 141-142).

${ }^{43}$ Cf. W. Müller-Lauter, «Nietzsches Lehre vom Willen zur Macht», Nietzsche Studien, 3, 1974 , p. 49 y, en general, 41-60.

${ }^{44} \mathrm{FW}$ : KSA III 626.

${ }^{45}$ JGB: KSA V 37. 
Lo que realmente hace Heidegger es, en primer lugar, radicalizar ontológicamente la comprensión y, en segundo lugar, ligar la interpretación originariamente a aquélla. En este segundo caso, Heidegger va más allá del planteamiento de Nietzsche no sólo al ampliar y especificar el radio de acción de la comprensión sino al estructurar y desglosar ‘dentro' de ésta a la interpretación. La circularidad y el carácter de la comprensión interpretativa reflejan de manera más acabada que en Nietzsche el carácter genérico antepredicativo inherente al logos. A pesar de la gran diferencia teóricamente inicial entre Nietzsche y Heidegger respecto del paradigma empleado -por sintetizar: modelo biológico frente a modelo ontológico-, puede establecerse una homogeneidad de fondo. El asunto del círculo hermenéutico es, en este sentido, un caso muy destacable. Para Heidegger también existe algo así como una tesis metacrítica; en Nietzsche tal tesis venía a significar la toma de conciencia definitiva de que la interpretación es un fenómeno, un macrofenómeno a partir del cual se entiende las distintas interpretaciones de la existencia: «un mismo texto permite incontables interpretaciones: no hay una interpretación "correcta"» ${ }^{46}$. Para Heidegger el círculo que tiene sus raíces en la comprensión también debe ser entendido y complementado con una toma de conciencia, a saber, la de los límites del propio interpretar. «El cumplimiento de las condiciones fundamentales de un posible interpretar radica, antes bien, en no empezar por desconocer las condiciones esenciales para llevarlo a cabo» ${ }^{47}$, esto es, aquellas derivadas de la fragilidad manifiesta del carácter interpretativo -comprensor de la existencia.

La propia idea de conocimiento que la tradición instauró viene a representar el contrapunto o límite de lo que de suyo debería ser una aproximación 'cognoscitiva' a la realidad. El sentido del ser en Heidegger y el carácter específico del devenir en Nietzsche no son asimilables a la estructura del conocimiento o, mejor dicho, a través del conocimiento es imposible acercarse, siquiera mínimamente, a tales conceptos. Precisamente por esto declara Nietzsche con rotundidad: «el carácter del mundo en devenir como informulable, como "falso", como "autocontradictorio". Conocimiento y devenir se excluyen ${ }^{48}$. De forma similar encontramos en Heidegger el convencimiento de que mientras se entienda el conocimiento como modo primario del ser en el mundo, quedará permanentemente oscurecida la estructura esencial del Dasein $^{49}$. El conocimiento es una forma de ser del ser en el mundo proveniente, en rigor, de una previa deficiencia del ver el mundo en el modo del 'curarse de', lo que habilita su comprensión como algo derivado y relativo y, en todo caso, nunca 'fundacional', en el sentido del fundamento.

${ }^{46}$ KSA XII 39: 2[120]. De ahí que el conocimiento sólo pueda ser interpretación y no explicación: «qué es lo único que puede ser el conocimiento? - 'interpretación', no 'explicación'» KSA XII 104: 2[86].

${ }^{47}$ SuZ, p. $203 / 171$.

${ }^{48}$ KSA XII 382: 9[89].

${ }^{49}$ Cf., por ejemplo, SuZ, pp. 79-80/71-72. 
El procedimiento para demostrar y alcanzar la relatividad y el carácter secundario del conocimiento en cuanto tal viene dado en nuestros autores a través de la investigación concienzuda y perspicaz de la trama y los mecanismos de legitimación normativos característicos del conocimiento. Concretando un poco más, lo que se pone fuertemente en cuestión es el elemento crucial del conocimiento como aparato de comprensión de la realidad, a saber: el sujeto. Para Nietzsche «el error consiste en la invención de un sujeto»50; para Heidegger hay un elemento común en todos los posicionamientos históricos del conocimiento que ha distorsionado radicalmente toda indagación verdaderamente originaria, esto es, el hecho de que «falta totalmente la cuestión de la forma de ser de este sujeto cognoscente»51. Prueba directa de esto es el esfuerzo por tematizar y proponer un 'nuevo' sujeto desde la experiencia del Übermensch y del Dasein como elementos galvanizadores en la 'reconstrucción' del conocimiento. Y todo ello arrojará el resultado siguiente: el carácter derivado y relativo del conocimiento es la consecuencia lógica del descubrimiento de la interpretación y la comprensión como factores de contacto originarios con el mundo.

Lo que Nietzsche denominaría moralización de la existencia, esto es, el imperio del logos como conocimiento y su modelo apolíneo y Heidegger entendería como triunfo omnímodo del conocimiento como presencia en la tradición metafísica a través del modelo de la Vorhandenheit, vienen a hacer del conocimiento algo definitivamente relativo. El conocimiento resulta para ambos algo definitivamente secundario visto desde la mismidad de lo dionisíaco y la Zuhandenheit. El conocimiento aparece ahora en toda su extensión y especificidad como problema y, por tanto, se ejecuta y consuma ese paso decisivo en la consideración tradicional del problema del conocimiento: del problema del conocimiento al conocimiento como problema.

Todo lo dicho puede ejemplificarse gráficamente en el siguiente esquema:

EL CONOCIMIENTO COMO PROBLEMA

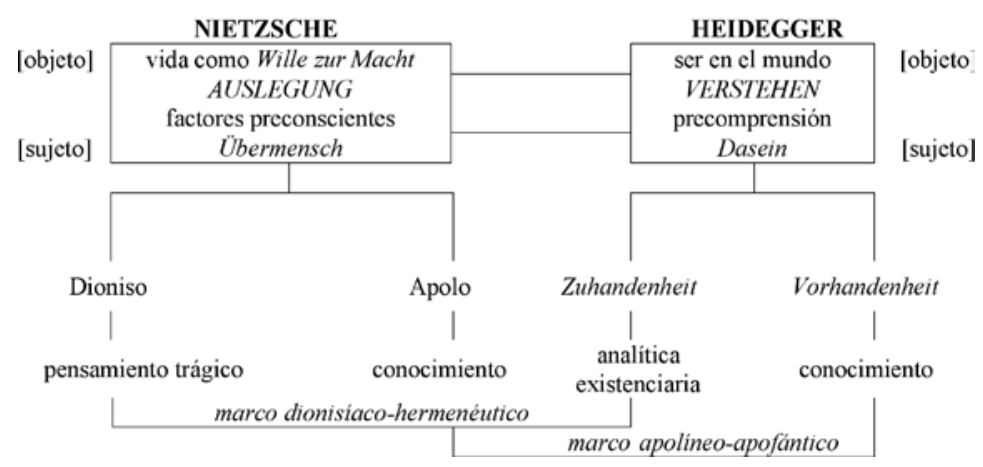

${ }^{50}$ KSA XII 137: 2[142]. «El concepto de unidad es derivado de nuestro concepto de 'yo' -nuestro más antiguo artículo de fe» KSA XIII 258: 14[79].

${ }^{51} \mathrm{SuZ}$, p. 81/73. 


\section{CONCLUSIONES}

La tesis de una continuidad esencial entre el concepto de interpretación y el de comprensión heideggeriano fue sugerida por Gadamer y aceptada, más que nada, intuitivamente pero no fue desarrollada sistemáticamente. Desde esta óptica, pretendimos, en primer lugar, reconstruir la 'ausencia' de Nietzsche en Sein und Zeit, frente a presencias conocidas y expresas como las de Kant o Husserl. Establecemos que Nietzsche representa en la obra de 1927 un interlocutor de primer orden. Con ello no sólo se clarifica la posición y alcance de Heidegger en Sein und Zeit sino que se manifiesta la continuidad, al menos en determinados enfoques. La identidad genérica de los conceptos interpretación y comprensión parece indicar que Sein und Zeit continúa, repite y prolonga la crítica nietzscheana del conocimiento y comparte fundamentalmente sus consecuencias. Puede decirse que Heidegger viene a cumplir el designio históricamente realizado de agotar la esencia de la subjetividad y proponer nuevas formas de pensamiento y que, en tal designio, es preciso hermanarlo con Nietzsche en un sentido muy peculiar. Según esto, Heidegger en Sein und Zeit no hace sino repetir la temática iniciada por Nietzsche y ensancharla mediante una radicalización ontológica.

Así las cosas, el concepto de interpretación anticipa el heideggeriano de comprensión y supuestamente la esfera y radio de acción de ambos es formalmente similar. Que Heidegger en la obra de 1927 amplia el concepto nietzscheano es, sin duda, un hecho absolutamente claro pero habría que apostillar que Sein und Zeit desarrolla y matiza el concepto nietzscheano únicamente desde un punto de vista ontológico que, en rigor, no añade ningún elemento sustancialmente nuevo. Por lo tanto, el tan cacareado concepto de comprensión heideggeriano puede entenderse, vistas las cosas desde un espectro amplio, como un desarrollo, eso sí, ontológicamente determinado, de la interpretación nietzscheana. De igual forma, aquel elemento tan crucial llamado a ocupar inexorablemente un puesto decisivo en la renovación hermenéutica, la precomprensión, está prediseñado en Nietzsche. Aquella estructura previa, la preestructura de la comprensión, se halla prefigurada y esbozada en los factores preconscientes, en tanto en cuanto determinantes de nuestras interpretaciones del mundo. El círculo hermenéutico, con sus diversos espesores y alcances, puede considerarse globalmente como una prolongación y desarrollo de la propia estructura interpretativa en la que, según Nietzsche, estamos por definición inmersos. Ciertamente Heidegger explicita y desarrolla ontológicamente la comprensión y la precomprensión de una forma más diáfana e incluso técnicamente de forma más acabada. Comparten, en suma, nuestros autores la puesta en práctica de un nuevo modelo reflexivo que permite últimamente repensar y reinaugurar el $\log o s$ y que cabalmente plenifica el sentido del giro copernicano que describen: del problema del conocimiento al conocimiento como problema. 
Ahora bien, si el paralelismo que hemos tratado de manifestar existe realmente, los interrogantes se acumulan. Por ejemplo: ¿por qué Nietzsche sólo aparece citado muy marginalmente? ¿Por qué no aparece mencionado al tratarse aspectos en los que el autor de Zaratustra dejó huella filosófica? ¿Es creíble establecer un corte tan drástico entre el Heidegger de los años 20 y el de los 30 respecto de la presencia de Nietzsche? En suma, ¿estamos ante una ausencia estratégica y calculada o, más bien, meramente casual? Falta, desde luego, la reconstrucción -no histórica sino ontológica-de la ausencia de Nietzsche en Sein und Zeit. A dilucidar este asunto, que quizás podría contribuir a 'resituar' a Nietzsche dentro de la filosofía contemporánea, hemos intentado contribuir. 